\title{
Retraction Note: Astragalus saponins affect proliferation, invasion and apoptosis of gastric cancer BGC-823 cells
}

Tao Wang ${ }^{1}$, Xiaoyan Xuan², Min Li ${ }^{2}$, Ping Gao ${ }^{1}$, Yuling Zheng ${ }^{3}$, Wenqiao Zang ${ }^{2^{*}}$ and Guogiang Zhao ${ }^{2^{*}}$

\section{Retraction}

This article has been retracted by the authors [1] because large portions of text have been duplicated from a number of previously published articles, including Tin et al., 2007 [2] and Auyeung et al., 2009 [3]. All authors agree with the retraction.

\section{Author details}

'Department of Hemato-tumor, The First Affiliated Hospital of Henan University of TCM, Zhengzhou, People's Republic of China. ${ }^{2}$ Department of Microbiology and Immunology, College of Basic Medical Sciences,

Zhengzhou University, Zhengzhou, People's Republic of China. ${ }^{3}$ Henan

University of TCM, Zhengzhou, People's Republic of China.

Published online: 07 September 2017

\section{References}

1. Wang T, Xuan X, Li M, Gao P, Zheng Y, Zang W, Zhao G. Astragalus saponins affect proliferation, invasion and apoptosis of gastric cancer BGC-823 cells. Diagn Pathol. 2013;8:179.

2. Tin MM, Cho CH, Chan K, James AE, Ko JK. Astragalus saponins induce growth inhibition and apoptosis in human colon cancer cells and tumor xenograft. Carcinogenesis. 2007;28(6):1347-55.

3. Auyeung KK, Cho CH, Ko JK. A novel anticancer effect of Astragalus saponins: transcriptional activation of NSAID-activated gene. Int J Cancer. 2009;125(5):1082-91.

\footnotetext{
* Correspondence: zangwenqiao@sina.com; zhaogq@zzu.edu.cn

The online version of the original article can be found under doi:10.1186/ 1746-1596-8-179

${ }^{2}$ Department of Microbiology and Immunology, College of Basic Medical

Sciences, Zhengzhou University, Zhengzhou, People's Republic of China
} 